\title{
Loss of Tdn catabolic genes by deletion from and curing of plasmid pTDN1 in Pseudomonas putida: rate and mode of loss are substrate and pH dependent
}

\author{
Christopher P. Saint* $†$ and W. A. Venables \\ School of Pure and Applied Biology, South Wing, University of Wales College of Cardiff, Cardiff CF1 3TL, UK
}

(Received 2 October 1989; revised 28 November 1989; accepted 5 January 1990)

\begin{abstract}
The ability to degrade aromatic amines and $m$-toluate ( $\mathrm{Tdn}^{+}$phenotype), encoded by plasmid pTDN1, was lost from Pseudomonas putida hosts after subculture in benzoate, succinate, acetate and glucose minimal medium, the fastest rate of loss occurring where benzoate was the substrate. Tdn- cells had either lost the entire pTDN1 plasmid or suffered a recombinational deletion of a specific $26 \mathrm{kbp}$ region. Proportional increase of $\mathrm{Tdn}^{-}$cells resulted from their growth-rate advantage, and additionally, where benzoate was the substrate, from its metabolism via the chromosomal ortho-cleavage pathway incorporating a short lag phase. The ratio of whole plasmid loss to deletion was substrate and $\mathrm{pH}$ dependent. Deletion of catabolic genes was not required for loss of pTDN1 but by comparison was a prerequisite for loss of TOL plasmid pWWO. It appeared that $m$-toluate and benzoate were channelled via chromosomally encoded benzoate oxygenase and dihydroxycyclohexadiene carboxylate dehydrogenase prior to pTDN1 encoded meta-cleavage.
\end{abstract}

\section{Introduction}

There have been several studies on the ability of various TOL plasmids to be 'cured' by growth on benzoate minimal medium. A common feature of TOL plasmids appears to be the ability to encode the dissimilation of $m$ and $p$-toluates, and benzoate via the same suite of enzymes involving a catechol 2,3-dioxygenase (C23O) meta-cleavage reaction (Fig. 1). The Pseudomonas hosts of these TOL plasmids possess an alternative chromosomally encoded route for benzoate metabolism which proceeds via the catechol 1,2-dioxygenase ortho-cleavage reaction. The plasmid pathway is induced by benzoate whilst the chromosomal pathway is induced by one of its intermediate products, cis,cis-muconate. This control system usually results in benzoate being metabolized via the plasmid-encoded pathway, as insufficient cis,cismuconate accumulates to fully induce the chromosomal pathway. However, where the plasmid pathway is non-

$\dagger$ Present address: Department of Plant Pathology, Waite Agricultural Research Institute, University of Adelaide, Glen Osmond, Adelaide, South Australia 5064, Australia.

\footnotetext{
Abbreviations: C23O, catechol 2,3-dioxygenase; HMSD, 2-hydroxymuconic semialdehyde dehydrogenase; HMSH, 2-hydroxymuconic semialdehyde hydrolase; NA, nutrient agar; NB, nutrient broth.
}

functional, cells growing by the chromosomal pathway become amplified due to faster growth rate on the substrate (Nakazawa \& Yokota, 1973; Williams \& Murray, 1974). Such amplified cells are plasmid 'cured' or have suffered plasmid deletions (Williams \& Worsey, 1976; Worsey \& Williams, 1977; Kunz \& Chapman, 1981; Pickup \& Williams, 1982; Pickup et al., 1983; Keil $\&$ Williams, 1985). The period of amplification varies considerably and occurs faster with TOL plasmids present in Pseudomonas MT14, MT15 and MT20 than with the archetypal TOL plasmid pWW0 of Pseudomonas putida mt-2 (PaW1) (Williams \& Worsey, 1976).

pTDN1 confers on its host the ability to metabolize the aromatic amines aniline, $m$ - and $p$-toluidine and also $m$-toluate, known collectively as the $\mathrm{Tdn}^{+}$phenotype (McClure \& Venables, 1986). The proposed pathway of dissimilation is TOL-like in that aromatic amines and $m$ toluate are channelled down a meta-cleavage pathway bearing isofunctional enzymes (Fig. 1). The wild-type isolate UCC22 bearing pTDN1 is a derivative of $P$. putida mt- 2 devoid of $\mathrm{pWW} 0$ but bearing a functional chromosomal ortho-cleavage pathway [McClure and Venables, 1986, 1987; Saint et al., 1990 (accompanying paper)]. The $\mathrm{Tdn}^{+}$phenotype was found to be unstable after subculture on benzoate minimal medium and $\mathrm{Tdn}^{-}$ cells showed no toluidine oxygenase, C23O, 2-hydroxy- 

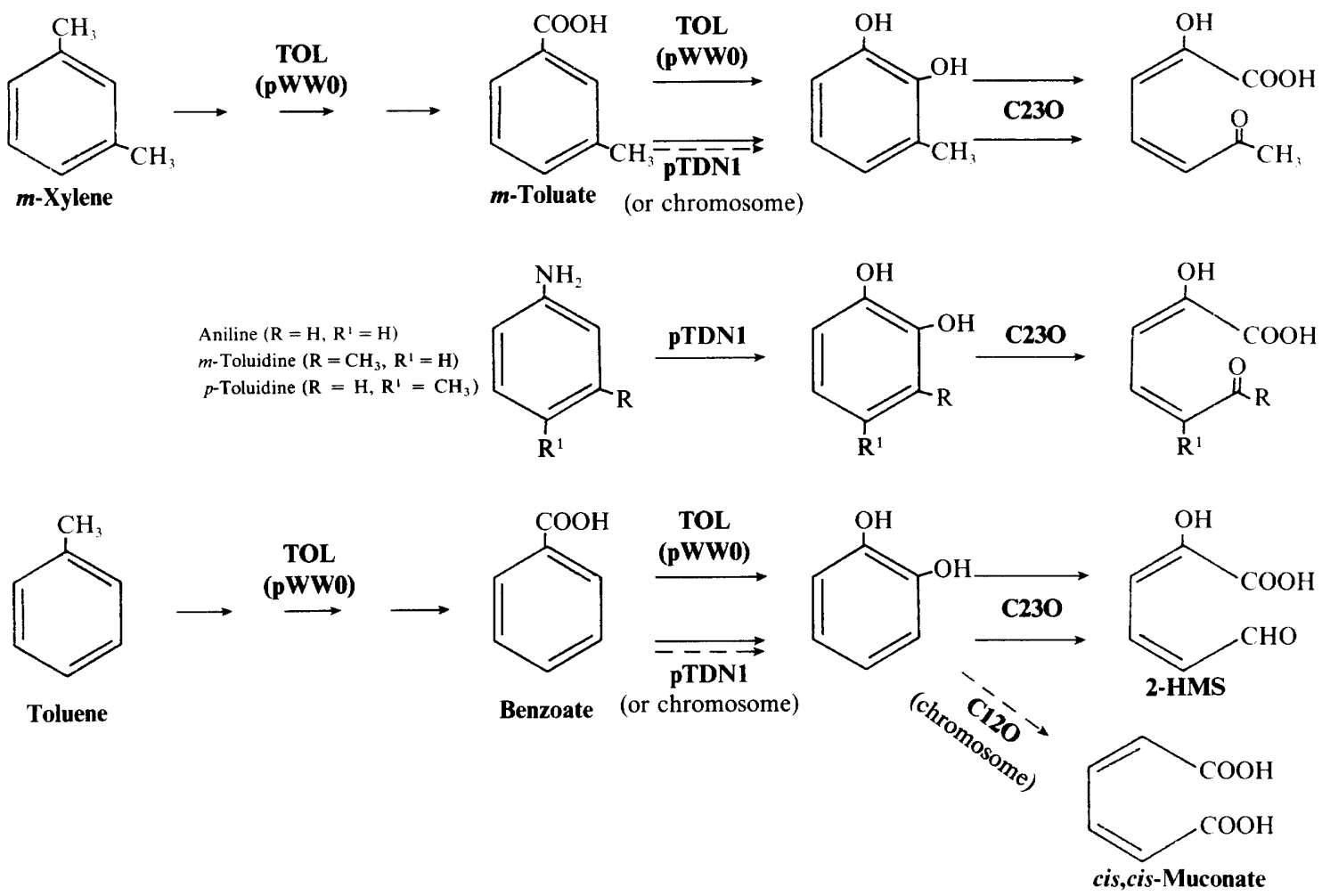

Fig. 1. Isofunctional steps of aromatic degradation encoded by pTDN1 and TOL (pWW0). Abbreviations: C23O, catechol 2,3dioxygenase; $\mathrm{C12O}$, catechol 1,2-dioxygenase; 2-HMS, 2-hydroxymuconic semialdehyde.

muconic semialdehyde dehydrogenase (HMSD) or 2hydroxymuconic semialdehyde hydrolase (HMSH) activities (McClure \& Venables, 1986). It seems reasonable to assume that benzoate can be metabolized via the plasmid-encoded pathway in strain UCC22.

MT14, MT15 and MT20 produce several classes of phenotypically distinguishable TOL-deletion mutants (Worsey \& Williams, 1977; Pickup \& Williams, 1982; Keil \& Williams, 1985) and it has been suggested that such TOL plasmids have regions of homology which act as 'hotspots' for recombinational deletion events (Williams et al., 1988). In the case of pWW0 growth of the host on benzoate was found to highlight two effects, either complete plasmid loss or deletion of a specific 39 $\mathrm{kbp}$ region bearing all the catabolic genes (Bayley et al., 1977). This region is bounded by two direct repeats, 1.4 $\mathrm{kbp}$ in size (Meulien et al., 1981). Deletion could therefore be ascribed to direct recombinational loss and recently it was shown that this occurs more frequently than plasmid loss (Williams et al., 1988). Similarly, we have found that the majority of $\mathrm{UCC} 22 \mathrm{Tdn}^{-}$cells, produced by growth on benzoate, contain a deleted derivative of pTDN1, a specific $26 \mathrm{kbp}$ deletion occurring between two direct repeats, and it is likely that the region lost contains all the Tdn genes (Saint et al., 1990).
Recent work has suggested different roles for benzoate in the production of cured and deleted TOL derivatives. Keshavarz et al. (1985) found that after prolonged chemostat culture on benzoate of $P$. putida PPK1, carrying a non-conjugative TOL plasmid, a switch to $\mathrm{m}^{-}$ toluate allowed recovery of plasmid-containing cells. They suggested that benzoate was affecting plasmid partitioning but its effect was not absolute, thereby allowing a residual plasmid-containing population to be maintained. Clarke \& Laverack (1984) found that plating strains containing TOL or naphthalene plasmids on high concentrations of benzoate yielded a high proportion of 'cured' colonies. Stephens \& Dalton (1987) also attribute a direct effect to benzoate and other weak lipophilic acids, possibly by disrupting the cell membrane and affecting plasmid partitioning. More recently, they have suggested that benzoate selectively inhibits the growth of plasmid-containing cells (Stephens \& Dalton, 1988). Williams et al. (1988) presented good evidence that for P. putida mt-2 at least, the differential growthrate theory is sufficient to explain benzoate 'curing'. They did experiments with wild-type and transposontagged pWW0 and found that growth at low $\mathrm{pH}$ and on other weakly lipophilic acids had no 'curing' effect. Also,

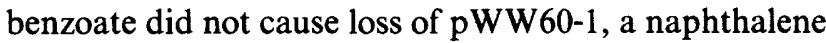
plasmid from the same incompatibility group as $\mathrm{pWW} 0$, 
which might be expected to be affected equally if benzoate acted on plasmid replication or partition.

This paper describes an investigation of the factors affecting stability of the Tdn phenotype in various $P$. putida hosts containing pTDN1; in some cases we compared the stability of TOL plasmid pWW0 under the same conditions. We also monitored the ratio of whole plasmid loss to plasmid deletion under different conditions.

\section{Methods}

Strains and plasmids. Pseudomonas putida and Escherichia coli strains and plasmids are listed in Table 1.

Curing experiments. Liquid and solid minimal media were prepared as described by Eaton \& Ribbons (1982); the $\mathrm{pH}$ was adjusted to 6.4 by excluding the appropriate amount of $\mathrm{NaOH}$. The sodium salts of benzoate, succinate and acetate were used and all carbon sources were used at $5 \mathrm{~mm}$ concentration except acetate $(10 \mathrm{~mm})$. Tryptophan (100 $\mu \mathrm{g} \mathrm{ml}^{-1}$ ) was added routinely to minimal media for convenience and standardization of experiments, after first demonstrating that its presence did not affect curing rates. Routinely, starter cultures and selective subcultures were incubated overnight, with shaking, at $30^{\circ} \mathrm{C}$, except where pTDN1- or pTDN1-543-containing strains were grown on $m$-toluate or benzoate, when they were incubated for up to $48 \mathrm{~h}$. Starting cultures were from single colonies inoculated into $m$-toluate minimal medium to ensure no curing prior to selective subculture. Starter culture integrity was monitored by plating suitable dilutions onto nutrient agar (NA) and spraying with $100 \mathrm{~mm}$-catechol. Wild-type cells $\left(\mathrm{Tdn}^{+} \mathrm{Ben}^{+}\right.$or $\left.\mathrm{Mtol}^{+} \mathrm{Ben}^{+}\right)$turned yellow due to the production of 2-hydroxymuconic semialdehyde from catechol by the plasmid- encoded $\mathrm{C} 23 \mathrm{O}$; strains lacking $\mathrm{C} 23 \mathrm{O}\left(\mathrm{Tdn}^{-} \mathrm{Ben}^{+}\right.$or $\left.\mathrm{Mtol}^{-} \mathrm{Ben}^{+}\right)$ remained white. In the case of $\mathrm{pWW} 0$-encoded $\mathrm{C} 23 \mathrm{O}$ activity an intense yellow colour was produced after about $1 \mathrm{~min}$; with pTDN1and pTDN1-543-containing strains colour took 3-4 min to fully develop and was less intense. A $0.1 \mathrm{ml}$ volume of a $10^{-2}$ dilution of starter culture in $0.95 \%(\mathrm{w} / \mathrm{v})$ sterile $\mathrm{NaCl}$ was inoculated into $5 \mathrm{ml}$ of appropriate medium. After incubation $0.1 \mathrm{ml}$ samples of $10^{-5}, 10^{-6}$ and $10^{-7}$ dilutions in $0.95 \%(\mathrm{w} / \mathrm{v})$ sterile $\mathrm{NaCl}$ were plated onto $\mathrm{NA}$ for screening by catechol spray test or estimation of retention of $\mathrm{Km}^{r}$. Colony counts were done concomitantly to estimate generation number. At least 1000 colonies were monitored per subculture. A $0.1 \mathrm{ml}$ volume of a $10^{-2}$ dilution was used to reinoculate fresh minimal medium and the process repeated. Where UCC 543 was monitored for retention of $\mathrm{Km}^{\mathrm{r}}$, colonies were sprayed with catechol and 50 white colonies replicated to NA and NA plus $25 \mu \mathrm{g}$ kanamycin $\mathrm{ml}^{-1}$. Where UCC5431 monitored 100 colonies were taken from NA and replicated to $\mathrm{NA}$ and $\mathrm{NA}$ plus $25 \mu \mathrm{g}$ kanamycin $\mathrm{ml}^{-1}$.

Transfer of pTDN1 and pWWO to a Rec ${ }^{-}$host. An overnight L-broth culture of $\mathrm{PpG} 1400$ was plated onto NA plus $100 \mu \mathrm{g}$ rifampicin $\mathrm{ml}^{-1}$. A $\operatorname{Rec}^{-}\left(\mathbf{U V}^{\mathrm{s}}\right) \mathrm{Trp}^{-} \mathrm{Rif}^{\mathrm{r}}$ mutant was retained and termed UCC30. Conjugations were done as described in the accompanying paper (Saint et al., 1990) using PaW1 and UCC22 as donors and selecting for transconjugants on minimal medium containing tryptophan and rifampicin plus $m$-toluate or aniline respectively. Both conjugations gave a transfer frequency of approximately $5 \times 10^{-4}$ per donor. Two transconjugants having the required phenotypes were retained and termed UCC31(pTDN1) and UCC32(pWW0).

Production of UCC52. UCC52 was one of twelve UCC22 derivatives bearing $\mathrm{Tn} 5$ in the chromosome used for producing pTDN $1:: \mathrm{Tn} .5$ mutations (Saint et al., 1990).

Plasmid isolation and analysis. Plasmid DNA was extracted by the procedure of Wheatcroft \& Williams (1981); restriction analysis was done as previously described by Saint et al. (1990).

\section{Table 1. Bacterial strains and plasmids}

Abbreviations: $\mathrm{Tdn}^{+}$, ability to grow on aromatic amines and $m$-toluate, Ben ${ }^{+}$, growth on benzoate; Mtol ${ }^{+}$, growth on $m$-toluate. $\mathrm{Km}$, kanamycin; Rif, rifampicin; $\mathrm{Rec}^{-}$, recombination deficient. C23O, catechol 2,3-dioxygenase. HA, HindIII-derived restriction fragment A of pTDN1.

\begin{tabular}{|c|c|c|}
\hline Strain & Plasmid & Notes and reference \\
\hline \multicolumn{3}{|c|}{ P. putida $\mathrm{mt}-2$} \\
\hline $\mathrm{UCC} 22$ & pTDN1 & $\mathrm{Tdn}^{+} \mathrm{Ben}^{+}$(Saint et al., 1990) \\
\hline UCC23 & pTDN1-3 & $\mathrm{Tdn}^{-} \mathrm{Ben}^{+}$produced by growth on benzoate (Saint et al., 1990) \\
\hline UCC52 & pTDN1 & $\begin{array}{l}\mathrm{Tdn}^{+} \mathrm{Ben}^{+} \mathrm{Km}^{\mathrm{r}} \text {. No benzoate metabolism via chromosomal ortho-pathway due to } \mathrm{Tn} 5 \text { insertion (this } \\
\text { paper) }\end{array}$ \\
\hline UCC521 & pTDN $1-3$ & $\mathrm{Tdn}^{-} \mathrm{Ben}^{-} \mathrm{Km}^{\mathrm{r}}$ produced by growth on succinate (this paper) \\
\hline KT2442 & & Rif $^{r}$ derivative of KT2440 (Franklin et al., 1981) \\
\hline $\mathrm{UCC} 24$ & pTDN1 & pTDN1 in KT2442 (McClure and Venables, 1987) \\
\hline UCC543 & pTDN1-543 & $\mathrm{Tdn}^{+} \mathrm{Ben}^{+} \mathrm{Km}^{\mathrm{r}} \mathrm{Tn} 5$ insertion in HA of pTDN1 in KT2442 (Saint et al., 1990) \\
\hline UCC5431 & pTDN1-5431 & $\mathrm{Tdn}^{-} \mathrm{Ben}^{+} \mathrm{Km}^{\mathrm{T}}$ derivative of pTDN1-543 (this paper) \\
\hline PaWl & pWW0 & Mtol $^{+}$Ben $^{+}($Williams \& Murray, 1974) \\
\hline PpG1400 & & $\operatorname{Rec}^{-} \operatorname{Trp}^{-}$(Hermann et al., 1979) \\
\hline UCC30 & & Rif ${ }^{r}$ derivative of $\mathrm{PpG} 1400$ (this paper) \\
\hline UCC 31 & pTDN1 & $\mathrm{Tdn}^{+} \mathrm{Ben}^{+} \mathrm{UCC} 30$ (this paper) \\
\hline $\mathrm{UCC} 32$ & pWW0 & $\mathrm{Mtol}^{+} \mathrm{Ben}^{+} \mathrm{UCC} 30$ (this paper) \\
\hline \multicolumn{3}{|l|}{ E. coli } \\
\hline $\mathrm{C} 600$ & pNMBI & pSUP5011 Mob replaced by pTDN1 derived C23O (gift of N. C. McClure) \\
\hline
\end{tabular}




\section{Results}

Stability of the Tdn phenotype under varying growth and pH conditions

Wild-type strain UCC22 and UCC24, both $\mathrm{Tdn}^{+}$, and $\mathrm{PaW} 1, \mathrm{Mtol}^{+}$, were subcultured on benzoate minimal medium and nutrient broth (NB) to compare the stability of Tdn and Mtol phenotypes. Growth of UCC22 and UCC 24 on benzoate minimal medium resulted in rapid loss of the $\mathrm{Tdn}$ phenotype and repeat experiments showed that after $20-25$ generations fewer than $0.1 \%$ of cells were $\mathrm{Tdn}^{+}$, which was the limit of detection (Fig. 2). There was a low level of Tdn phenotype loss on NB which showed some oscillation, seen most clearly with UCC24 (Fig. 2). This suggests that although loss occurred it did not confer a large growth advantage in this medium. Loss of Mtol phenotype by $\mathrm{PaW} 1$ was much slower in benzoate minimal medium compared to loss of Tdn phenotype by UCC22 and UCC24, and in repeat experiments rates of loss were less consistent than seen with the Tdn phenotype. No loss of Mtol phenotype from $\mathrm{PaW} 1$ was detectable after NB subculture.

Plasmids were extracted from $12 \mathrm{Tdn}^{-}$isolates from each growth survey. In every case isolates contained an identical deleted derivative of pTDN1 equivalent to pTDN1-3 (Saint et al., 1990), in which HindIII derived restriction fragments carrying catabolic genes were lost, whilst HA and one copy of HE were retained (Fig. 3, lane 2). Also, $\mathrm{Tdn}^{-}$cells containing similarly deleted pTDN1 derivatives were produced after growth and subculture of UCC 22 and UCC24 on succinate, acetate and glucose minimal medium. This prompted a thorough investigation of the factors involved in loss of the Tdn phenotype on various media.

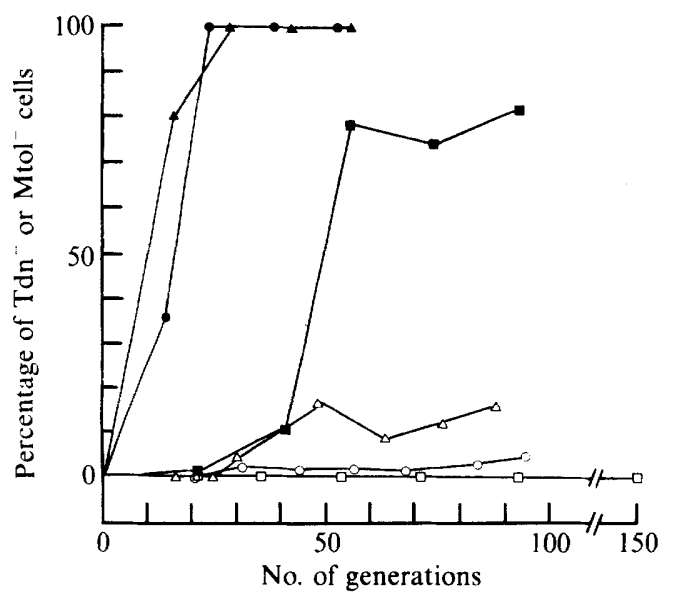

Fig. 2. Loss of $\mathrm{Tdn}^{+}$phenotype from UCC22 and UCC24 and loss of $\mathrm{Mtol}^{+}$phenotype from PaWl after subculture on NB and benzoate minimal medium. $\triangle, \mathrm{UCC} 24 ;-\mathrm{UCC} 22 ; \square, \mathrm{PaW} 1$ after subculture on benzoate minimal medium; $\triangle$, UCC24; O, UCC22; $\square, \mathrm{PaW} 1$ after subculture on NB.

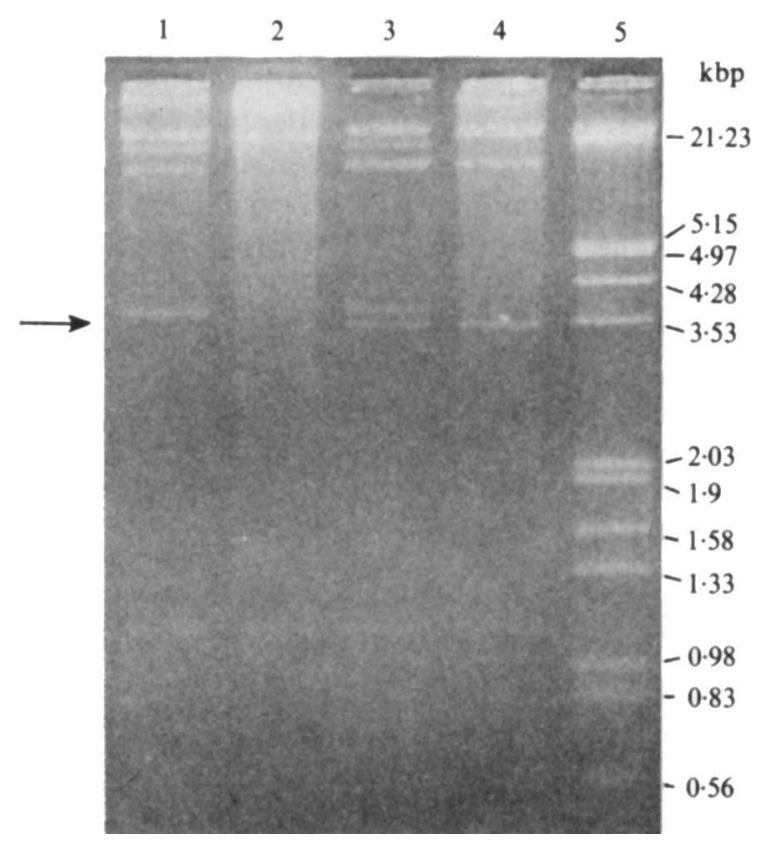

Fig. 3. Restriction digestion of pTDN1 and pTDN1-543 and their deleted derivatives with HindIII. Lane 1, pTDN1; 2, pTDN1-3; 3 , pTDN1-543; 4, pTDN1-5431; 5; $\lambda$ DNA digested with HindIII and EcoRI. The arrow indicates the novel $3.5 \mathrm{kbp}$ fragment derived from Tn5 present in pTDN1-543 and pTDN1-5431.

As plasmid-deleted and plasmid-cured $\mathrm{Tdn}^{-}$cells can only be distinguished by DNA isolation, a timeconsuming process, further studies on the modes of loss of Tdn phenotype on various substrates were done using UCC543 bearing pTDN1-543. pTDN1-543 bears a Tn5 insertion in HA of pTDN1 (Saint et al., 1990) outside the region deleted to give pTDN1-3. Therefore, where pTDN1-3-like deletion derivatives of pTDN1-543 arise $\mathrm{Tn} 5$ is retained and cells are $\mathrm{Tdn}^{-} \mathrm{Km}^{\mathrm{r}}$; where the whole plasmid, and therefore $\mathrm{Tn} 5$ is lost, cells become $\mathrm{Tdn}^{-} \mathrm{Km}^{\mathrm{s}}$.

Loss of the Tdn phenotype from UCC543 was monitored after growth and subculture on benzoate, glucose, succinate and acetate minimal medium at $\mathrm{pH}$ 6.8 (Fig. $4 a$ ) and pH 6.4 (Fig. $4 b$ ). Concomitantly, the percentage of $\mathrm{Tdn}^{-}$cells retaining $\mathrm{Km}^{\mathrm{r}}$ at each subculture was determined, revealing the ratio of plasmidcured to plasmid-deleted cells (Fig. 5). There was little difference in the rates of loss of Tdn phenotype at $\mathrm{pH} 6 \cdot 8$ or $\mathrm{pH} 6.4$ on all substrates and the kinetics of phenotype loss were similar to the wild-type $\mathrm{UCC} 22$ bearing pTDN1, indicating that the presence of Tn 5 in pTDN1 does not affect stability. The ratio of deletion to whole plasmid loss was substrate and $\mathrm{pH}$ dependent. Total plasmid loss was more rapid at $\mathrm{pH} 6.8$ on all substrates (Fig. 5a). For example, the rate of loss of Tdn phenotype in succinate minimal medium was similar at either $\mathrm{pH}$ such that after 50 generations no $\mathrm{Tdn}^{+}$cells were 


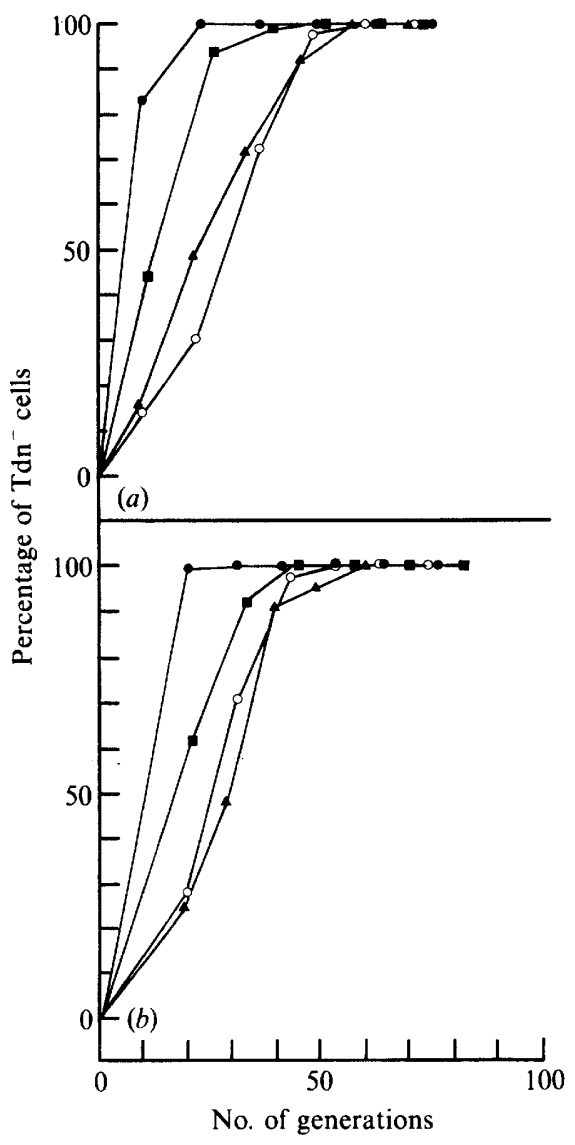

Fig. 4. Loss of $\mathrm{Tdn}^{+}$phenotype after subculture of UCC543 at pH 6.8 (a) and $\mathrm{pH} 6.4(b)$ in minimal medium supplemented with: benzoate; $\boldsymbol{\square}$, succinate; $\boldsymbol{\Delta}$, acetate; $O$, glucose.

detectable (Fig. 4), but at pH $6.470 \%$ of such cells were $\mathrm{Km}^{\mathrm{r}}$ (plasmid deleted) whereas at $\mathrm{pH} 6.8$ only $26 \%$ were $\mathrm{Km}^{\mathrm{r}}$. Growth on acetate minimal medium at either $\mathrm{pH}$ value gave the highest level of whole plasmid loss. $\mathrm{Tdn}^{-} \mathrm{Km}^{\mathrm{s}}$ and $\mathrm{Tdn}^{-} \mathrm{Km}^{\mathrm{r}}$ isolates (twelve from each experiment) were examined for plasmid content. $\mathrm{Tdn}^{-} \mathrm{Km}^{\mathrm{s}}$ isolates contained no plasmid DNA whereas $\mathrm{Tdn}^{-} \mathrm{Km}^{\mathrm{r}}$ isolates contained a deleted derivative of pTDN1-543 (Fig. 3, lanes 3 and 4) still bearing the characteristic $3.5 \mathrm{kbp}$ novel fragment derived from $\operatorname{Tn} 5$. A $\mathrm{Tdn}^{-} \mathrm{Km}^{\mathrm{r}}$ isolate (UCC5431) was retained in order to investigate the stability of the deleted plasmid. This isolate was grown in benzoate, succinate and acetate minimal medium and loss of the $\mathrm{Km}^{\mathrm{r}}$ marker was monitored. Loss was most evident where acetate was the substrate, reaching $>99 \%$ after 84 generations (Fig. 6). After 92 generations, $73 \%$ of succinate-grown cells were $\mathrm{Km}^{\mathrm{r}}$ and after 91 generations, $34 \%$ of benzoate-grown cells were $\mathrm{Km}^{\mathrm{r}}$ (Fig. 6). Plasmid analysis revealed that $\mathrm{Km}^{\mathrm{r}}$ cells always contained pTDN1-5431 and $\mathrm{Km}^{\mathrm{s}}$ cells contained no plasmid. Growth on NB produced some

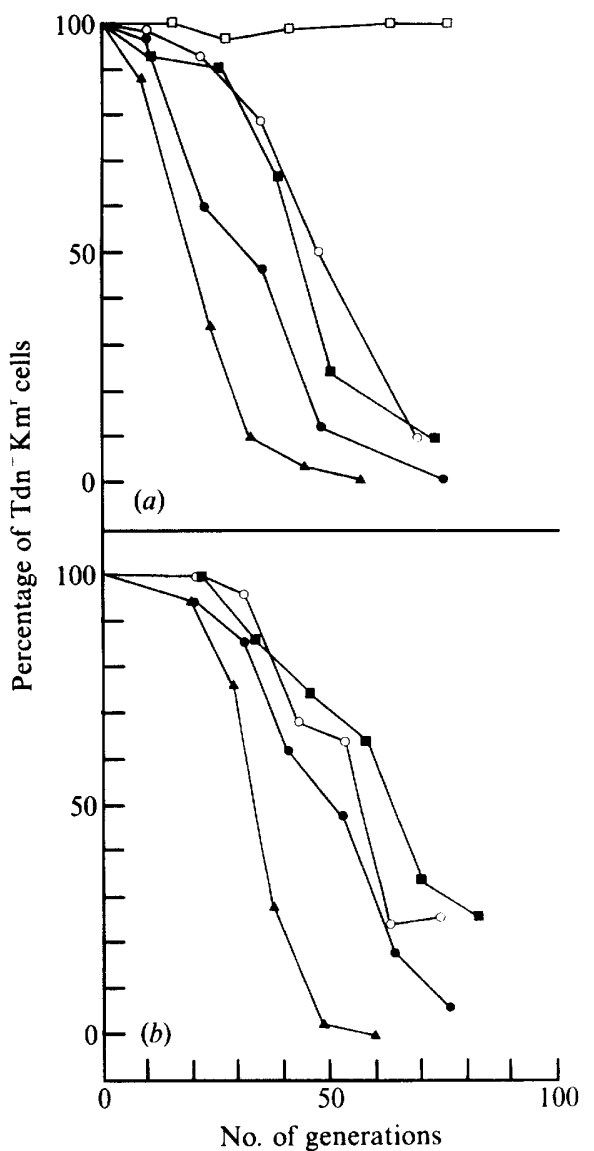

Fig. 5. Proportion of plasmid-deleted $\left(\mathrm{Km}^{\mathrm{r}}\right)$ to plasmid-cured $\left(\mathrm{Km}^{\mathrm{s}}\right)$ Tdn- UCC543 cells after subculture at $\mathrm{pH} 6.8(a)$ and $\mathrm{pH} 6.4(b)$ in minimal medium supplemented with: $\boldsymbol{O}$, benzoate; $\boldsymbol{\square}$, succinate; $\boldsymbol{\Lambda}$, acetate; $O$, glucose. $\square, \mathrm{NB}$ ( $\mathrm{pH} 6 \cdot 8$ ).

loss of $\mathrm{Km}^{\mathrm{r}}$ but this was not detected until 50 generations of growth, and reached only $1 \%$ after $>75$ generations.

\section{UCC52 is defective in the benzoate ortho-cleavage pathway}

After subculture of Tn 5 insertion mutant UCC52 on benzoate minimal medium and plating of appropriate dilutions to minimal medium containing $5 \mathrm{~mm}-m$-toluate and $0.5 \mathrm{~mm}$-succinate all colonies retained the ability to grow on $m$-toluate. An inactive meta-cleavage pathway, produced by plasmid deletion or loss, allows conversion of $m$-toluate to 3-methylcatechol only by the chromosomal benzoate oxidation gene products, but accumulation of black oxidation products from such a conversion were not seen.

However, when stability studies were done on the UCC52 Tdn phenotype after subculture in NB, succinate, acetate, benzoate and glucose minimal medium (Fig. 7 ), loss of phenotype correlated well with that seen in 


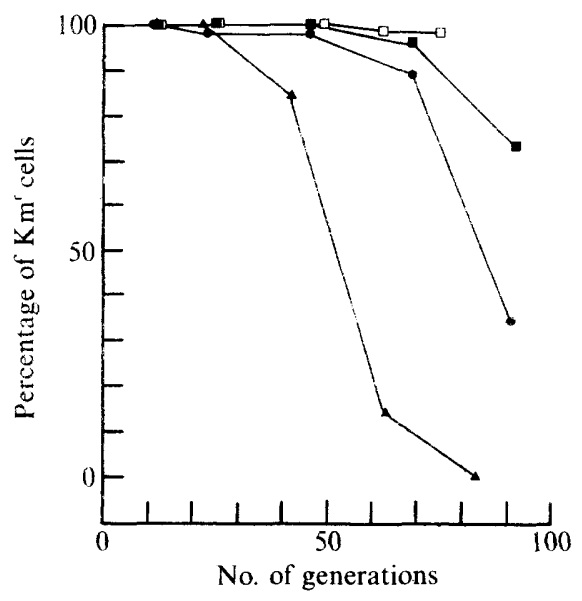

Fig. 6

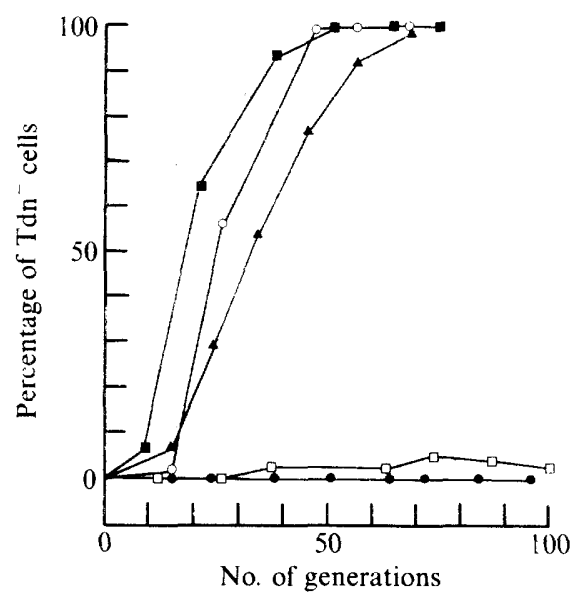

Fig. 7

Fig. 6. Loss of pTDN1-5431 from UCC5431 after subculture on minimal medium (pH 6.8) containing: $\bullet$, benzoate; $\boldsymbol{\square}$, succinate; $\boldsymbol{\Delta}$, acetate. $\square, \mathrm{NB}(\mathrm{pH} 6 \cdot 8)$.

Fig. 7. Loss of $\mathrm{Tdn}^{+}$phenotype from UCC52 after subculture on minimal medium containing: O, glucose. $\square, \mathrm{NB}(\mathrm{pH} 6 \cdot 8)$.

UCC22 (Fig. 2) and UCC24 (Fig. 4a) with the exception of benzoate. Growth on benzoate minimal medium was followed for a maximum of 92 generations but loss of Tdn phenotype was never seen. This demonstrated that $\operatorname{Tn} 5$ insertion had resulted in a benzoate-specific stability of pTDN1, and therefore the Tdn phenotype. Plasmid extraction revealed that $\mathrm{Tdn}^{-}$isolates of UCC52 contained a plasmid equivalent to pTDN1-3 (Fig. 3, lane 2). One such isolate was retained and termed UCC521. $\mathrm{Tdn}^{-}$isolates were always Ben-, strongly suggesting that the $\mathrm{Tn} 5$ insertion had affected the chromosomally encoded benzoate ortho-cleavage pathway. UCC521 was used to confirm this hypothesis. Spectrophotometric analysis (data not shown) revealed the following: UCC521 accumulated 3-methylcatechol from $m$-toluate and catechol from benzoate and $E$. coli containing pNMB1, bearing the cloned $\mathrm{C} 23 \mathrm{O}$ gene from pTDN1, converted accumulated 3-methylcatechol to 2-hydroxy-6oxohepta-2,4-dienoate and catechol to 2-hydroxymuconic semialdehydes. Conversion of benzoate to catechol was detectable only after a $10 \mathrm{~h}$ incubation of UCC521 with the substrate; subsequently, during a $2 \mathrm{~h}$ period, benzoate completely disappeared from the medium. Buildup of 3-methylcatechol and its oxidation products was slow, media progressively darkening after $24 \mathrm{~h}$.

\section{Stability of Tdn and Mtol phenotypes in a Rec- host}

$\mathrm{Rec}^{-}$strains UCC 31 and UCC 32 were subcultured on benzoate minimal medium at $\mathrm{pH} 6.8$ and $\mathrm{pH} 6.4$ and succinate minimal medium at $\mathrm{pH}$ 6.8. No loss of Mtol phenotype was seen for UCC 32 on any of these media after 90 generations of growth. For UCC 31 , rates of loss of Tdn phenotype were significantly reduced (Fig. 8). For example, after 20 generations of growth on succinate minimal medium, $73 \%$ of UCC24 cells were $\mathrm{Tdn}^{-}$(Fig. $4 a$ ) whereas only $11 \%$ of UCC 31 cells were $\mathrm{Tdn}^{-}$(Fig. 8). However, at this stage of growth a similar percentage of $\mathrm{Tdn}^{-}$UCC24 cells had completely lost pTDN1 (Fig. $5 a$ ). After growth for 24 generations on benzoate $36 \%$ of UCC31 cells were still $\mathrm{Tdn}^{+}$(Fig. 8), whereas at the same stage no $\mathrm{Tdn}^{+}$cells were detectable with UCC22 (Fig. 2) or UCC24 (Fig. 4a). Tdn $^{-}$derivatives of UCC31 were screened for the presence of plasmid DNA but it was not detectable in isolates obtained after $<20$ generations,

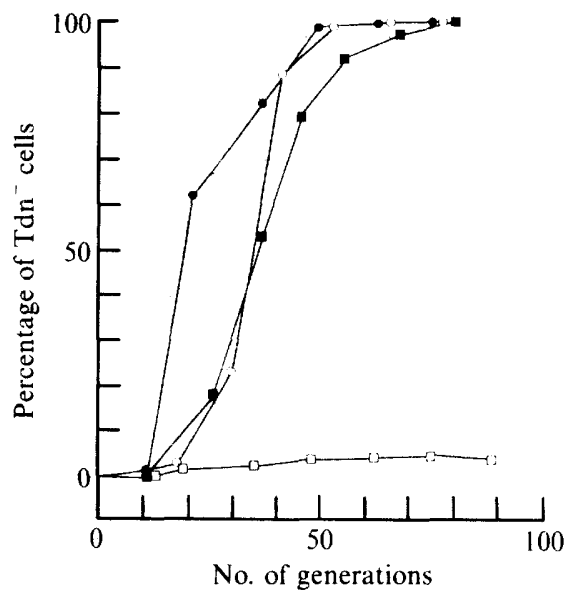

Fig. 8. Plasmid curing of pTDN1 from $\mathrm{Rec}^{-} \mathrm{UCC} 31$ in minimal medium supplemented with: 0 , benzoate $(\mathrm{pH} 6.8) ; \mathrm{O}$, benzoate $(\mathrm{pH}$ 6.4) $\square$, succinate (pH 6.8). $\square, \mathrm{NB}$ (pH 6.8). 
indicating there was no recombinational loss of $\mathrm{Tdn}$ phenotype. It was noticeable that reduction of $\mathrm{pH}$ affected whole plasmid loss especially in the initial 40 generations. Loss of Tdn phenotype, and therefore plasmid, accelerated slowly at $\mathrm{pH} 6.4$ but the point at which $100 \%$ loss was approached was similar at both $\mathrm{pH}$ 6.8 and pH 6.4 (Fig. 8). This effect was seen when whole plasmid loss was followed in benzoate minimal medium at $\mathrm{pH} 6.8$ and $\mathrm{pH} 6.4$ with UCC24 (Fig. $5 a, b$ ). There was, however, a difference between the overall rates of plasmid loss from UCC 24 and UCC 31 in that loss from UCC 31 on benzoate and succinate minimal medium approached $100 \%$ at an earlier stage than UCC24, even though loss of Tdn phenotype occurs more rapidly in this strain. This suggests that selective pressure to lose pTDN 1 is alleviated by deletion of the catabolic genes, a conclusion which is also supported by the lower rate of loss observed with the deleted plasmid pTDN1-5431 (Fig. 6).

Presence of Tdn function confers a growth-rate disadvantage

When agar containing succinate minimal medium was used to screen for loss of Tdn phenotype after $2 \mathrm{~d}$ incubation, colonies which turned yellow when sprayed with catechol $\left(\mathrm{Tdn}^{+}\right)$were approximately half the size of colonies which remained white $\left(\mathrm{Tdn}^{-}\right)$. This suggested that $\mathrm{Tdn}^{-}$cells possessed a significant growth-rate advantage and this might be detectable by standard growth-rate experiments. (Table 2). It was not clear whether KT2442 had a significant growth rate advan- tage over UCC23 (bearing deleted plasmid pTDN1-3) but both these strains appeared to have a growth-rate advantage over UCC22 (bearing pTDN1) on benzoate, succinate and glucose minimal medium and UCC.23 showed a growth-rate advantage over UCC22 on acetate minimal medium. In the case of UCC30 the presence of pTDN1 (UCC31) reduced the growth rate of the host strain on succinate minimal medium significantly and more than halved the growth rate on benzoate minimal medium. However, the large difference in growth rate seen between UCC 23 and UCC22 and UCC 30 and UCC 31 on benzoate minimal medium was probably also attributable to the variation of efficiency in benzoate metabolism by the chromosomal ortho- and plasmid meta-cleavage pathways. Lowering the $\mathrm{pH}$ to 6.4 also lowered growth rates of UCC 22 on benzoate, glucose and acetate minimal medium and UCC 31 on benzoate minimal medium. This suggests that in the case of pTDN1 a faster growth rate results in greater levels of whole plasmid loss (Fig. 5, Fig. 8).

There are two possible explanations why no loss of Mtol phenotype is seen after subculture of UCC32 in benzoate: that the growth rate of UCC 32 on benzoate is equal to or in excess of UCC 30, thereby conferring no growth-rate advantage on plasmid-cured cells, or that recombinational deletion is a prerequisite for whole plasmid loss. The growth rate of UCC 32 on benzoate minimal medium is less than that of UCC 30 (Table 2), so the second explanation appears to be the case.

No evidence was found for the inhibition of growth in the presence of benzoate of cells containing pTDN 1 or the deleted derivative pTDN1-3 (Table 2). K T2442 and

Table 2. Effects of the presence of $p W W 0, p T D N 1$ or $p T D N 1-3$ and the $p H$ of the growth medium on the growth rates of $P$. putida strains

All substrates were at $5 \mathrm{mM}$ concentration except acetate $(10 \mathrm{mM})$. Values are means of two independent experiments. ND, Not determined.

\begin{tabular}{|c|c|c|c|c|c|c|c|}
\hline \multirow[b]{2}{*}{ Strain } & \multirow[b]{2}{*}{$\mathrm{pH}$} & \multicolumn{6}{|c|}{ Growth rate $\left(\Delta O \mathrm{DD}_{600} \mathrm{~h}^{-1}\right)$ on: } \\
\hline & & Benzoate & Succinate & Glucose & Acetate & $m$-Toluate & Aniline \\
\hline UCC $30^{*}$ & $6 \cdot 8$ & 0.693 & 0.721 & ND & ND & ND & ND \\
\hline \multirow{2}{*}{ UCC 31 (pTDN1)* } & $6 \cdot 8$ & $0 \cdot 340$ & 0.506 & ND & ND & ND & ND \\
\hline & $6 \cdot 4$ & $0 \cdot 292$ & ND & ND & ND & ND & ND \\
\hline UCC32 (pWW0)* & $6 \cdot 8$ & 0.521 & ND & ND & ND & ND & ND \\
\hline PaWl (pWW0) & $6 \cdot 8$ & 0.641 & ND & ND & ND & ND & ND \\
\hline \multirow{2}{*}{$\mathrm{UCC} 22(\mathrm{pTDN} 1)$} & 6.8 & 0.546 & 0.796 & 0.641 & 0.619 & $0 \cdot 130$ & $0 \cdot 162$ \\
\hline & $6 \cdot 4$ & 0.505 & 0.796 & 0.597 & 0.554 & ND & ND \\
\hline \multirow[t]{2}{*}{ UCC23 (pTDN1-3) $\dagger$} & $6 \cdot 8$ & 0.721 & 0.875 & 0.666 & 0.693 & ND & ND \\
\hline & & (ND) & $(0 \cdot 875)$ & $(0 \cdot 753)$ & $(0 \cdot 641)$ & ND & ND \\
\hline UCC52 (pTDN1) $\dagger$ & 6.8 & 0.462 & $(0.753)$ & ND & $(0 \cdot 641)$ & 0.092 & $0 \cdot 187$ \\
\hline KT2442 & $6 \cdot 8$ & $0 \cdot 721$ & 0.924 & 0.693 & 0.597 & ND & ND \\
\hline
\end{tabular}

* Cells grown in the presence of $100 \mu \mathrm{g}$ tryptophan $\mathrm{ml}^{-1}$.

† Values in parentheses are from experiments in which cells were grown in the presence of 5 mm-benzoate as well as the substrate indicated. 
UCC 30 entered exponential growth after $3 \mathrm{~h}$ in benzoate minimal medium, PaW1 and UCC 32 after $5 \mathrm{~h}$ and UCC52, UCC22 and UCC 31 after approximately $9 \mathrm{~h}$. UCC52 and UCC22 took approximately $24 \mathrm{~h}$ to reach exponential phase in aniline or $m$-toluate minimal medium and growth rates for both substrates were slow. These long lag phases did not appear to be associated with enzyme induction since when cells were subcultured to fresh medium the pattern was repeated.

Exponential growth of UCC52, UCC22 and UCC 31 on benzoate minimal medium started after a similar time period to the chromosomally encoded disappearance of benzoate from media inoculated with UCC521. There was an accumulation of the oxidation products of 3methylcatechol at the onset of exponential growth of UCC 22 and UCC52 on $m$-toluate, which coincided with an identical accumulation seen in $m$-toluate minimal medium inoculated with UCC521. This suggests that the chromosomally encoded benzoate oxygenase and dihydroxycyclohexadiene carboxylate dehydrogenase are responsible for the initial steps of benzoate and $m$-toluate dissimilation in $P$. putida strains containing pTDN1.

\section{Discussion}

Cells bearing pTDN1 rapidly lost the Tdn phenotype after growth in minimal medium on a variety of substrates. Loss of the Tdn phenotype occurred by two mechanisms, either deletion of a $26 \mathrm{kbp}$ section bearing the catabolic genes or by complete plasmid loss. We attribute proportional increase of $\mathrm{Tdn}^{-}$cells after growth on succinate, acetate and glucose minimal medium to their demonstrable growth-rate advantage. Such instability on a range of substrates has not previously been demonstrated for catabolic plasmids. Loss of the Tdn phenotype after growth on benzoate minimal medium was extremely rapid and we attribute this to three factors. Plasmid-deleted or cured cells in the presence of benzoate have a dual growth-rate advantage. Firstly, there is a reduction in metabolic load, i.e. the same growth advantage seen in succinate, glucose and acetate minimal medium. Secondly, such cells express the orthocleavage pathway of benzoate utilization which bestows a further growth-rate advantage. These two factors together may explain why there is such a large growth rate difference between $\mathrm{UCC} 22$ and $\mathrm{UCC} 23$ and UCC 30 and UCC 31 on benzoate minimal medium (Table 2). Thirdly, the long lag phases of cells expressing the pTDN1- encoded meta-cleavage pathway for benzoate utilization allows plasmid-deleted and cured cells to become established during the early phases of culture. This can clearly be seen by comparing growth of UCC 22 in benzoate minimal medium when the initial inoculant was aniline-grown cells, all containing functional pTDN1, with those of NB-grown cells, where a small percentage of inoculant cells are plasmid-cured/deleted. From a NB starter, UCC22 entered exponential growth after approximately $6 \mathrm{~h}$ and exhibited a similar growth rate to UCC23. This reflects the rapid establishment of plasmid-deleted and cured cells in the culture. There would no doubt be variation in this lag phase in repeated experiments as each NB starter culture would show variation in numbers of plasmid-cured/deleted cells. This also highlights the importance of commencing experiments with standard inocula. Repeat experiments using inocula prepared on $m$-toluate minimal medium gave reproducible rates of Tdn phenotype loss. Stephens \& Dalton (1987) found that rates of curing of TOL plasmid pWW15 were not reproducible on certain substrates though it is not clear whether the nature of the inoculum was a contributary factor to this result. Clearly, using non-selective inocula can affect curing rates appreciably.

When PaW1 was subcultured in NB, no $\mathrm{Mtol}^{-}$ segregants were identified. However, when pTDN1containing strains were treated likewise $\mathrm{Tdn}^{-}$clones were readily detected (Fig. 2). This reflects relative unselected levels of loss of the two phenotypes when cells are under no metabolic pressure. Williams et al. (1988) suggested that for $\mathrm{PaW} 1$ such segregants were present at as high a frequency as $10^{-2}-10^{-3}$. Our data suggests such segregants are in fact present at frequencies $<10^{-3}$, as we screened at least 1000 colonies per subculture. Only a small percentage of $\mathrm{Tdn}^{-} \mathrm{UCC} 543$ cells were $\mathrm{Km}^{\mathrm{s}}$ after NB subculture (Fig. 5a), indicating that under nonselective conditions deletion occurs more frequently than whole plasmid loss. The greater frequency of deletion detected for pTDN 1 when compared to $\mathrm{pWW} 0$ may be due to its direct repeats, the 'hotspots' for recombinational loss, being longer and closer together than those of pWW0.

The long lag phase of cells bearing pTDN 1 in benzoate minimal medium raises an interesting question concerning the expression of the chromosomal ortho-cleavage pathway in such cells. During this long lag phase one would expect the ortho-cleavage pathway to become fully induced but this does not happen. The growth kinetics of UCC22 and UCC52 are comparable on benzoate minimal medium, which is direct evidence for an inoperative ortho-cleavage pathway in UCC22 equivalent to the situation in UCC52. Additionally, if the orthocleavage pathway normally operated in UCC22 then loss of Tdn phenotype would be reduced to a level equivalent to those seen during growth on succinate, acetate and glucose minimal medium, as there would be no additional ortho- versus meta-cleavage growth-rate advantage. This suggests that the ortho-cleavage pathway is 
repressed in the presence of complete pTDN1. If such repression occurs it is not clear how this affects the chromosomally encoded benzoate oxygenase and dihydroxycylohexadiene carboxylate dehydrogenase as little is known concerning the normal induction of these enzymes. Our results suggest that in cells bearing pTDN1 both benzoate and $m$-toluate are initially metabolized via these enzymes and their products subsequently channelled down the plasmid-encoded meta-cleavage pathway. Conclusive proof that these two enzymes are required for such conversions could be gained by transfer of pTDN1 to a benzoate-oxygenasedeficient mutant of $P$. putida $\mathrm{mt}-2$ such as that described by Cuskey $\&$ Sprenkle (1988).

There was no evidence for a direct effect of benzoate on plasmid loss as proposed for certain TOL plasmids (Stephens and Dalton, 1987, 1988). The presence of benzoate did not inhibit growth of plasmid-containing cells (Table 2) and undissociated benzoate (at $\mathrm{pH} 6.4$ ) was not a more effective curing agent (Fig. 4b). It appeared that for pTDN1, the rates at which whole plasmid loss or plasmid deletion occurred were governed by the type of substrate and the $\mathrm{pH}$ of growth. Both deletion and whole plasmid loss appeared to occur concomitantly, with the former occurring more rapidly (Fig. 5). Deletion is not a prerequisite for whole plasmid loss as revealed by curing studies with UCC31 (Fig. 8). When cell populations were $100 \% \mathrm{Tdn}^{-}$, loss of $\mathrm{Km}^{\mathrm{r}}$ still occurred (Figs 4 and 5); also, UCC5431 exhibited loss of $\mathrm{Km}^{\mathrm{r}}$ after subculture (Fig. 6) indicating loss of deleted plasmid. Total loss of plasmid was most pronounced after growth of the host on acetate minimal medium (Figs 5 and 6). One can envisage a metabolic advantage to cells which have completely lost a large catabolic plasmid and this is likely to be most pronounced with a substrate such as acetate that has a low energy yield. Plasmid loss was greater in minimal medium on all substrates at $\mathrm{pH} 6.8$ than at $\mathrm{pH} 6.4$ (Fig. 5). This increase in plasmid loss as neutral $\mathrm{pH}$ is approached has been found in other studies. Curing of R-plasmid TP181 from $E$. coli using various phenolic compounds was critically affected by the $\mathrm{pH}$ of the growth medium (Lakshmi et al., 1987, 1989) with curing found to be most efficient at $\mathrm{pH} 7-7 \cdot 2$. Such alterations in $\mathrm{pH}$ undoubtedly affect cell viability and therefore growth rate (Table 2). Faulty plasmid partitioning is likely to be more prevalent amongst more rapidly dividing cells at $\mathrm{pH} 6.8$.

Stephens \& Dalton (1987) found that for TOL plasmid pWW 15 deletions always occurred prior to plasmid loss. In the case of TOL plasmid pWW0 Williams et al. (1988) showed that plasmid deletion occurred far more frequently than plasmid loss after subculture of the host on benzoate minimal medium. We have demonstrated that deletion of the $39 \mathrm{kbp}$ region from $\mathrm{pWW} 0$ appears to be a prerequisite for plasmid loss as $\mathrm{Rec}^{-} \mathrm{UCC} 32 \mathrm{did}$ not yield plasmid-cured cells after subculture on benzoate minimal medium. Williams et al. (1988) found that a deleted derivative of $\mathrm{pWW} 0$ was stably maintained after subculture on benzoate minimal medium. This suggests that whole plasmid loss occurs as a direct result of recombination and does not occur subsequent to this event. In the case of pTDN1, clearly recombination is not required for whole plasmid loss.

We have demonstrated a complex set of factors which determine stability of Tdn catabolic genes on pTDN1. Clearly, therefore, the stability of different TOL plasmids and plasmids such as pTDN1, bearing isofunctional catabolic genes to TOL plasmids, are governed by different factors. This is because the nature of the replicon bearing the catabolic genes is the major influence on their stability. Therefore, it is not possible to put forward a single theory which accounts for the proportional increase of plasmid-deleted and cured cells under various growth conditions.

C.P.S. was supported by SERC Fellowship GR/E49531 awarded to W.A.V.

\section{References}

Bayley, S. A., Duggleby, C. J., Worsey, M. J., Williams, P. A., HARDY, K. G. \& BRODA, P. (1977). Two modes of loss of the TOL function from Pseudomonas putida mt-2. Molecular and General Genetics 154, 203-204.

Clarke, P. H. \& Laverack, P. D. (1984). Growth characteristics of Pseudomonas strains carrying catabolic plasmids and their cured derivatives. FEMS Microbiology Letters 24, 109-112.

Cuskey, S. M. \& SPRENKLe, A. B. (1988). Benzoate-dependent induction from the OP2 operator-promoter region of the TOL plasmid pWW0 in the absence of known plasmid regulatory genes. Journal of Bacteriology 170, 3742-3746.

EATON, R. W. \& RibBons, D. W. (1982). Metabolism of dibutylphthalate and phthalate by Micrococcus sp. Strain 12B. Journal of Bacteriology 151, 48-57.

Franklin, F. C. H., Bagdasarian, M., Bagdasarian, M. M. \& TIMmis, K. N. (1981). Molecular and functional analysis of the TOL plasmid pWW0 from Pseudomonas putida and cloning of genes for the entire regulated aromatic ring meta cleavage pathway. Proceedings of the National Academy of Sciences of the United States of America 78, 7458-7462.

Hermann, M., Garg, G. K. \& Gunsalus, I. C. (1979). Fertility factors in Pseudomonas putida: selection and properties of high-frequency transfer and chromosomal donors. Journal of Bacteriology 137, 10231033.

KeIl, H. \& Williams, P. A. (1985). A new class of TOL plasmid deletion mutants in Pseudomonas putida MT15 and their reversion by tandem gene amplification. Journal of General Microbiology 131, 1023-1033.

Keshavarz, T., Lilly, M. D. \& Clarke, P. H. (1985). Stability of a catabolic plasmid in continuous culture. Journal of General Microbiology 131, 1193-1203.

KUNZ, D. A. \& ChAPMAN, P. J. (1981). Isolation and characterization of spontaneously occurring TOL plasmid mutants of Pseudomonas putida HSI. Journal of Bacteriology 146, 952-962.

LaKshmi, V. V., Padma SRIdHaR \& Polasa, H. (1987). Elimination of multidrug-resistant plasmid in bacteria by plumbagin, a compound derived from a plant. Current Microbiology 16, 159-161. 
Lakshmi, V. V., Padma Sridhar \& Polasa, H. (1989). Loss of plasmid linked antibiotic resistance in Escherichia coli on treatment with some phenolic compounds. FEMS Microbiology Letters 57, 275-278.

McClure, N. C. \& Venables, W. A. (1986). Adaptation of Pseudomonas putida mt-2 to growth on aromatic amines. Journal of General Microbiology 132, 2209-2218.

MCClure, N. C. \& Venables, W. A. (1987). pTDN1, a catabolic plasmid involved in aromatic amine catabolism in Pseudomonas putida mt-2. Journal of General Microbiology 133, 2073-2077.

Meulien, P., Downing, R. G. \& BrodA, P. (1981). Excision of the 40 $\mathrm{kb}$ segment of the TOL plasmid from Pseudomonas putida $\mathrm{mt}-2$ involves direct repeats. Molecular and General Genetics 184, 97-101.

Nakazawa, T. \& Yokota, T. (1973). Benzoate metabolism in Pseudomonas putida (arvilla) mt-2: demonstration of two benzoate pathways. Journal of Bacteriology 115, 262-275.

Pickup, R. W. \& Williams, P. A. (1982). Spontaneous deletions in the TOL plasmid pWW20 which give rise to the B3 regulatory mutants of Pseudomonas putida MT20. Journal of General Microbiology 128, 1385-1390.

Pickup, R. W., Lewis, R. J. \& Williams, P. A. (1983). Pseudomonas sp. MT14, a soil isolate which contains two large catabolic plasmids, one a TOL plasmid and one coding for phenylacetate catabolism and mercury resistance. Journal of General Microbiology 129, 153-158.

Saint, C. P., McClure, N. C. \& Venables, W. A. (1990). Physical map of the aromatic amine and $m$-toluate catabolic plasmid pTDN1 in Pseudomonas putida: location of a unique meta-cleavage pathway. Journal of General Microbiology 136, 615-625.
StePhenS, G. M. \& DAlton, H. (1987). The effect of lipophilic weak acids on the segregational stability of TOL plasmids in Pseudomonas putida. Journal of General Microbiology 133, 1891-1899.

StePHENS, G. M. \& DALtoN, H. (1988). The effect of lipophilic weak acids on the segregational stability of TOL plasmids in Pseudomonas putida MT15 during growth in chemostat culture. FEMS Microbiology Letters 55, 175-180.

WheAtCroft, R. \& Williams, P. A. (1981). Rapid methods for the study of both stable and unstable plasmids in Pseudomonas. Journal of General Microbiology 124, 433-437.

Williams, P. A. \& MURRAY, K. (1974). Metabolism of benzoate and the methylbenzoates by Pseudomonas putida (arvilla) mt-2: evidence for the existence of a TOL plasmid. Journal of Bacteriology 120, 416423

Williams, P. A. \& Worsey, M. J. (1976). Ubiquity of plasmids in coding for toluene and xylene metabolism in soil bacteria: evidence for the existence of new TOL plasmids. Journal of Bacteriology 125, 818-828.

Williams, P. A., Taylor, S. D. \& GibB, L. E. (1988). Loss of toluenexylene catabolic genes of TOL plasmid pWW0 during growth of Pseudomonas putida on benzoate is due to a selective growth advantage of 'cured' segregants. Journal of General Microbiology 134, 2039-2048.

WoRsey, M. J. \& Williams, P. A. (1977). Characterization of a spontaneously occurring mutant of the TOL20 plasmid in Pseudomonas putida MT20: possible regulatory implications.' Journal of Bacteriology 130, 1149-1158. 